\title{
From headwaters to estuary: Distribution and fate of halogenated flame retardants (HFRs) in a river basin near the largest HFR manufacturing base in China
}

\author{
Xiaomei Zhen ${ }^{\mathrm{a}, \mathrm{b}, \mathrm{c}}$, Jianhui Tang ${ }^{\mathrm{a}, *}$, Lin Liu ${ }^{\mathrm{a}, \mathrm{c}}$, Xinming Wang ${ }^{\mathrm{b}}$, Yanan Li $^{\mathrm{a}, \mathrm{c}}$, Zhiyong Xie $^{\mathrm{d}}$ \\ a Key Laboratory of Coastal Environmental Processes and Ecological Remediation, Yantai Institute of Coastal Zone Research, CAS, Yantai 264003, China \\ b State Key Laboratory of Organic Geochemistry, Guangzhou Institute of Geochemistry, Chinese Academy of Sciences, Guangzhou 510640, China \\ c University of Chinese Academy of Sciences, Beijing 100049, China \\ d Helmholtz-ZentrumGeesthacht, Centre for Materials and Coastal Research, Institute of Coastal Research, Max-Planck-Strasse 1, Geesthacht 21502,Germany
}

\section{H I G H L I G H T S}

- Halogenated flame retardants (HFRs) were investigated in a river basin near a largest manufacturing base in Asia.

- Dechlorane plus and decabromodiphenylethane (DBDPE) were the dominant compounds in water samples.

- DBDPE was the predominant compound in the sediment samples

- Point sources, atmospheric deposition and land runoff are the major sources for HFRs in River.

- Estuarine maximum turbidity zone (MTZ) plays important roles on the distributions of HFRs in estuary.

\section{A R T I C L E I N F O}

\section{Article history:}

Received 13 August 2017

Received in revised form 7 October 2017

Accepted 10 October 2017

Available online $\mathrm{xxxx}$

Editor: Jay Gan

\section{Keywords:}

HFRs

DPs

DBDPE

Xiaoqing River

Laizhou Bay

\section{G R A P H I C A L A B S T R A C T}



\begin{abstract}
A B S T R A C T
With the gradual phasing out of polybrominated diphenyl ethers (PBDEs), market demands for alternative halogenated flame retardants (HFRs) are increasing. The Laizhou Bay area is the biggest manufacturing base for brominated flame retardants (BFRs) in China, and the Xiaoqing River is the largest and most heavily contaminated river in this region. Water and sediment samples were collected from the headwaters to the estuary of the Xiaoqing River to investigate the distribution and fate of HFRs [i.e., PBDEs, alternative brominated flame retardants (aBFRs) and dechlorane plus (DPs). In the water samples, DPs was the most abundant flame retardant (median: $11.7 \mathrm{ng} / \mathrm{L}$ ), followed by decabromodiphenylethane (DBDPE) (5.92 ng/L). In the sediment samples, DBDPE was the predominant flame retardant (39.5 ng/g dw), followed by decabromodiphenyl ether (BDE 209) $(2.81 \mathrm{ng} / \mathrm{g} \mathrm{dw})$. The levels of DBDPE exceeded those of BDE 209 in most samples, indicating the overwhelming replacement of BDE 209 by DBDPE in this area. In the river section of this study, point source and atmospheric deposition followed by land runoff were the major factors influencing the distribution of HFRs, whereas in the estuary, riverine discharge, the estuarine maximum turbidity zone (MTZ), and hydrodynamic parameters played more important roles. Manufacturing is a significant source of contamination of the Xiaoqing River basin through atmospheric deposition and wastewater discharge.
\end{abstract}

C 2017 Published by Elsevier B.V.

\footnotetext{
* Corresponding author.

E-mail address: jhtang@yic.ac.cn (J. Tang).
} 


\section{Introduction}

Halogenated flame retardants (HFRs) are used to reduce the flammability of manufactured materials such as plastics, textiles, polyurethane foam, and furnishings in order to stop the outbreak or spread of fire (Liu et al., 2016). HFRs comprised 31\% of the global flame retardant market in 2013 (Flamretardants-online, 2014). However, HFRs are known to be harmful both to the environment and to humans due to their persistence, bio-accumulation, and long-range transport potential (Jia et al., 2011, Liu et al., 2015, Xie et al., 2011).

The three commercial mixtures of PBDEs, namely penta-BDE, octaBDE and deca-BDE, have been identified and listed as persistent organic pollutants (POPs) under Annex A of the Stockholm Convention (www. pops.int). Such restrictions on the use of PBDEs have led to the use of aBFRs, such as pentabromotoluene (PBT), 2,3-diphenylpropyl-2,4,6tribromophenyl ether (TBP-DBPE), pentabromoethylbenzene (PBEB), hexabromobenzene (HBB), bis-(2-ethylhexyl)-tetrabromophthalate (BEH-TEBP) and 2-ethylhexyl-2,3,4,5-tetrabromobenzonate (-EH-TBB) 1,2-bis(2,4,6- tribromophenoxy)ethane (TBE) and DBDPE. Hence, all of these compounds occur in soil, air, sediment and water (Liu et al., 2016, Xie et al., 2011, Zhen et al., 2016, Zheng et al., 2015). Unfortunately, some of these aBFRs have been shown to possess characteristic of POPs (Covaci et al., 2011, He et al., 2012, Xie et al., 2011). DPs, which are highly chlorinated flame retardants, have been used in plastic materials and electrical materials such as wires and cables (Zheng et al., 2015). DPs have been determined in various environmental medium (Jia et al., 2011, Zheng et al., 2015), and have been shown to be bioavailable, bioaccumulative, and potentially toxic ( $\mathrm{Wu}$ et al., 2012).

HFRs, which have a high octanol-water partition coefficient $\left(\mathrm{K}_{\mathrm{ow}}\right)$, tend to bind to particulates, leading to their deposition in sediment. The occurrence of PBDEs and DPs in water and sediments has previously been investigated (Ju et al., 2016, Kim et al., 2016, Mahmood et al., 2015, Sun et al., 2013, Xiong et al., 2016). Pan et al., 2011 reported high $\sum$ PBDE concentrations in sediment samples from two sites in the Xiaoqing River, which empties into Laizhou Bay. Although growing attention has been paid to aBFRs or novel BFRs (NBFRs), data of NBFRs in aquatic environments in north China are still lacking. For example, previous studies focused on the distribution of NBFRs in the atmosphere, soil, and sediment of north China (Lin et al., 2013; Zhen et al., 2016a; Zheng et al., 2015). Besides, Wang et al., 2017 reported on three NBFRs in seawater from the Bohai Sea. However, specific investigation of NBFRs in freshwater environments is of great significance for figuring out overall contamination status of NBFRs in north China. To the best of our knowledge, this is the first study on DBDPE as an alternative for BDE 209 in aquatic environments in north China. Oceans are also been considered major sinks for HFRs. Several studies have shown that, in China, rivers leading to the sea were polluted by HFRs (Chen et al., 2013, Mahmood et al., 2015, Zhang et al., 2009).

Previous studies have demonstrated that HFR contaminations of various environmental media, including the atmosphere, soil, and human serum(Jin et al., 2011, Wang et al., 2014, Zhao et al., 2013), were impacted by HFR manufacturing (Chen et al., 2013, Jin et al., 2011). It is noted that the biggest manufacturing base for BFRs in China is located on the south coast of Laizhou Bay (Pan et al., 2011). Thus, further research was necessary to better understand the influence of the BFR manufacturing on the Xiaoqing River Basin.

In this present study, water and sediment samples were collected in April 2014 from the Xiaoqing River basin. In all samples, 20 HFR chemicals were measured, including ten PBDEs, eight aBFRs, and two DPs. The aims of this study were to i) identify the occurrences and distribution characteristics of the target compounds in the water and sediment sample, ii) explore the fates of the HFRs in the river-estuary system, and iii) pinpoint the possible sources of HFRs in the Xiaoqing River Basin.

\section{Materials and methods}

\subsection{Materials}

The target analytes included 10 PBDEs (BDE 28, BDE 47, BDE 66, BDE 85, BDE 99, BDE 100, BDE 154, BDE 153, BDE 183, and BDE 209), 8 aBFRs (PBT, PBEB, TBP-DBPE, HBB, EH-TBB, TBE, BEH-TEBP, and DBDPE) and 2 DPs (syn-DP and anti-DP). All PBDE standards mixtures and the eight aBFRs were purchased from Wellington Laboratories (Guelph, Ontario, Canada). The syn-DP and anti-DP were purchased from AccuStandard (New Haven, CT). PCB209 was used as a surrogate standard, and PCB 208 was used as an internal standard. These two standards were both purchased from AccuStandard (New Haven, CT). ${ }^{13} \mathrm{C}-\mathrm{HBB}$ and ${ }^{13} \mathrm{C}$ BDE138 were used as another two surrogate standards and were purchased from Cambridge Isotope Laboratories. Acetone for gas chromatography ECD and FID was acquired from Merck (Germany), and dichloromethane (DCM) and hexane were redistilled before use. Neutral silica gel (80-100 mesh) was extracted using DCM, and anhydrous sodium sulfate was baked at $450{ }^{\circ} \mathrm{C}$ for $5 \mathrm{~h}$. Laboratory glassware was cleaned and oven-dried at $450{ }^{\circ} \mathrm{C}$ for $5 \mathrm{~h}$ prior to use.

\subsection{Sample collection}

Laizhou Bay is located in the southern Bohai Sea, a semi-enclosed interior sea in China. It is a shallow bay, with an average depth of $10 \mathrm{~m}$, and covers $10 \%$ of the Bohai Sea area. Since the 1970s, Laizhou Bay has been severely contaminated by anthropogenic pollution from the rivers and waste water pipelines that discharge into it (Jiang et al., 2017). The Xiaoqing River is the second largest freshwater river, after the Yellow River, which drains into Laizhou Bay. The Xiaoqing River is an artificial $233 \mathrm{~km}$ river channel that passes through several important urban and industrial cities in Shandong Province, including Jinan, Zibo, Binzhou, Weifang, and Dongying, before finally discharging into Laizhou Bay. In 2017, the water quality of $60 \%$ of the Xiaoqing River was below the National Surface Water Standard Class IV level (HCEPA, 2016). In addition, high levels of PBDEs and perfluoroalkyl substances (PFASs) have been reported in this river (Heydebreck et al., 2015, Pan et al., 2011).

One sampling campaign was performed in Xiaoqing River Basin and all samples were collected along the Xiaoqing River into the Laizhou Bay in spring (April 19-23, 2014). The river samples were collected from the headwater to the estuary in the bridges or dams across the river, while the Laizhou Bay samples were collected within one day from a fishing coat. At each station, 3-5 water samples at different depths and 2-4 sediment samples at different spots were collected and then mixed into one sample. Water samples were collected from 30 stations, including 19 sites from the Xiaoqing River (X1-X19) and 11 sites from the estuary and Laizhou Bay (X20-X30; Fig. 1). Between stations X19 and X20, there is a floodgate in the river to prevent seawater from flowing up the estuary to the upstream sector. A stainless steel bucket was used to collect $\sim 20 \mathrm{~L}$ of surface water per sample. The collected water was stored in a brown glass bottle, kept cool (at around $4{ }^{\circ} \mathrm{C}$ ), and transported to the laboratory within $24 \mathrm{~h}$. A peristaltic pump was used to pump water samples, first through a glass fiber filter (GFF, $0.7 \mu \mathrm{m}$, Whatman) to trap particulates, and then through an Amberlite ${ }^{\circledR}$ XAD- 2 resin column $(30 \times 4 \mathrm{~cm}$ i.d) to capture the dissolved phase HFRs. All water samples were filtered within $48 \mathrm{~h}$ of collection. All glass fiber filters were baked for $5 \mathrm{~h}$ at $450{ }^{\circ} \mathrm{C}$ prior to use, and XAD-2 resin columns were cleaned with redistilled methanol, 1:1 hexane: acetone, and dichloromethane (DCM) for $16 \mathrm{~h}$ each before sampling. In addition, 22 surface sediment samples ( 0 $5 \mathrm{~cm}$ ) were collected with a stainless steel grab bucket, and then sealed in clean polyethylene (PE) bags. The filters and sediment samples were stored at $-20{ }^{\circ} \mathrm{C}$ until further analysis; columns were stored at $4{ }^{\circ} \mathrm{C}$ until extraction. 




Fig. 1. Map of the sampling stations in the Xiaoqing River Basin.

\subsection{Sample extraction}

Before extraction, the sediment samples were freeze-dried, ground, and homogenized. The water filters were also freeze-dried to remove any remaining water. All samples were spiked with 20 ng of PCB 209, 10 ng of ${ }^{13} \mathrm{C}-\mathrm{HBB}$, and $10 \mathrm{ng}$ of ${ }^{13} \mathrm{C}$-BDE 138 as surrogate standards. Activated copper was added to the flasks to remove elemental sulfur from the samples. Sediments and filters were both Soxhlet extracted via DCM for $24 \mathrm{~h}$. Water columns were extracted in a modified Soxhlet apparatus for 24 h using DCM (Moller et al., 2010). Water column extracts were frozen before cleanup to eliminate any remaining water. Extracts were concentrated to $\sim 2-3 \mathrm{~mL}$ using a rotary evaporator. The cleanup method used was based on previous studies (Xie et al., 2011; Zhen et al., 2016b). Briefly, all concentrated extracts were cleaned on a $2.5 \mathrm{~g}$ silica column ( $10 \%$ water deactivated) topped with $3 \mathrm{~g}$ of anhydrous sodium sulfate. The column was then eluted with $20 \mathrm{~mL}$ of hexane. The eluent was further concentrated to approximately $100 \mu \mathrm{L}$ in iso-octane and spiked with $20 \mathrm{ng}$ of $\mathrm{PCB} 208$ (as internal standard) prior to quantification.

\subsection{Quantification}

Quantification of all target analytes was performed via an Agilent 7890A gas chromatograph equipped with an Agilent 5975C mass spectrometer in the electron capture negative ionization mode. A $15 \mathrm{~m} \times$ $0.25 \mathrm{~mm} \times 0.1 \mu \mathrm{m}$ DB-5HT capillary column (J\&W GC column, Agilent) was used to separate the BDE 209 and DBDPE. A DB-5MS (30 m $\times$ $0.25 \mathrm{~mm} \times 0.1 \mu \mathrm{m}$, J\&W GC column, Agilent) was used to measure the remaining analytes (9 PBDEs, 8 aBFRs, syn-DP and anti-DP). Both column temperature programs were based on a previous study (Zhen et al., 2016b). The MS transfer line was held at $300{ }^{\circ} \mathrm{C}$, and both the ion source and quadruple temperature were $150{ }^{\circ} \mathrm{C}$. The injection volume was $1 \mu \mathrm{L}$, and the splitless injection mode was used.

After removing carbonates, the sediment total organic carbon (TOC) was determined using an elemental analyzer (CHNS Vario Ei III, Elementar). Water samples were filtered through a cellulose acetate membrane, and then dissolved organic carbon (DOC) was also measured with the Vario TOC analyzer. Salinity was measured using a portable multi-parameter water quality meter (YSI Pro Plus, YSI Inc., USA).

\section{5. $Q A$ and $Q C$}

Recoveries and blanks were monitored throughout the sampling and the analytical measurements. For the water columns, the mean recoveries for PCB $209,{ }^{13} \mathrm{C}-\mathrm{HBB}$, and ${ }^{13} \mathrm{C}$-BDE138 were $87 \pm 14 \%, 98 \% \pm$ $22 \%$, and $77 \% \pm 17 \%$, respectively. For the filters, the mean recoveries for PCB 209, ${ }^{13} \mathrm{C}$-HBB and ${ }^{13} \mathrm{C}$-BDE 138 were $99 \pm 10 \%, 106 \% \pm 14 \%$, and $135 \% \pm 27 \%$, respectively. In the sediment samples, the mean recoveries for PCB 209, ${ }^{13} \mathrm{C}$-HBB and ${ }^{13} \mathrm{C}$-BDE 138 were $0.53 \pm 17 \%, 87 \% \pm$ $10 \%$, and $103 \% \pm 37 \%$, respectively. Method detection limits (MDLs) were calculated based on the averages of the solvent blanks plus three standard deviations of the blanks. The MDL ranges of the PBDEs, aBFRs, and DPs across all filters were 0.0001-0.01 ng/L, 0.00004$0.008 \mathrm{ng} / \mathrm{L}$, and $0.016-0.14 \mathrm{ng} / \mathrm{L}$, respectively. The MDL ranges of the columns were $0.0001-0.044 \mathrm{ng} / \mathrm{L}$ for the PBDEs, $0.0005-0.07 \mathrm{ng} / \mathrm{L}$ for the aBFRs, and $0.02-0.19 \mathrm{ng} / \mathrm{L}$ for the DPs. The MDL ranges (PBDEs, aBFRs, and DPs) of the sediments were $0.004-0.034 \mathrm{ng} / \mathrm{g}, 0.001-$ $0.002 \mathrm{ng} / \mathrm{g}$, and $0.0007-0.07 \mathrm{ng} / \mathrm{g}$, respectively. In this study, HFR concentrations were not corrected with recoveries, as discussed further below. If the measured values were below the MDLs, the levels were considered not detected (n.d.). In the following sections, $\sum$ HFR concentration represented the sum of all the analyte concentrations, and $\sum$ PBDE concentration represented the sum of 10 PBDE congeners concentrations. In addition, $\sum$ aBFR concentrations represented the sum of the eight alternative brominated flame retardants concentrations, and DPs concentration represented the sum of the syn-DP and anti-DP concentrations.

\section{Results and discussion}

\subsection{Concentrations of HFRs in the water samples}

Ten PBDEs, eight aBFRs, and two DPs were quantified (Table 1). Table S1 shows the concentrations of all analytes in the dissolved and particulate phases of the water samples and in the sediment samples. According to Table S1, the particulate phase concentrations of the target compounds were invariably higher than their dissolved concentrations, which might be attributed to differences in the content and/or properties of the suspended particulate matter of these two phases. The 
Table 1

Concentrations of HFRs in the water and sediment of the Xiaoqing River Basin.

\begin{tabular}{|c|c|c|c|c|c|}
\hline \multirow[t]{2}{*}{ Compounds } & \multicolumn{3}{|c|}{ Water(n = 30, unit: ng/L) } & \multicolumn{2}{|c|}{$\begin{array}{l}\text { Sediment }(\mathrm{n}=22 \text {, } \\
\text { unit: } \mathrm{ng} / \mathrm{g} \mathrm{dw})\end{array}$} \\
\hline & Dissolved & Particulate & $\begin{array}{l}\text { Median of } \\
\text { sum }^{a}\end{array}$ & Range & Median \\
\hline BDE28 & $0.0003-0.066$ & $0.0003-0.160$ & 0.006 & n.d.-1.99 & 0.021 \\
\hline BDE47 & $0.0002-0.022$ & n.d. -0.170 & 0.008 & n.d.-2.13 & 0.089 \\
\hline BDE66 & n.d. -0.001 & n.d. -0.0210 & 0.003 & n.d. -0.038 & 0.004 \\
\hline BDE100 & n.d. -0.001 & n.d. -0.037 & 0.0001 & n.d. -0.430 & 0.013 \\
\hline BDE99 & n.d. -0.002 & n.d. -0.170 & 0.004 & n.d. -2.10 & 0.053 \\
\hline BDE85 & n.d. & n.d. -0.009 & n.d. & n.d. -0.180 & n.d. \\
\hline BDE154 & n.d. -0.001 & n.d. -0.025 & 0.001 & n.d. -0.210 & 0.008 \\
\hline BDE153 & n.d. & n.d. -0.056 & 0.002 & n.d. -0.680 & 0.047 \\
\hline BDE183 & n.d. -0.005 & $0.0002-0.110$ & 0.005 & n.d. -0.430 & 0.059 \\
\hline BDE209 & n.d. -0.780 & n.d.-11.4 & 0.290 & n.d.-7.62 & 2.81 \\
\hline$\sum$ PBDEs & $0.001-0.80$ & $0.026-11.5$ & 0.410 & $0.130-10.0$ & 3.66 \\
\hline $\overrightarrow{\mathrm{PBT}}$ & n.d. -0.007 & n.d.-2.04 & 0.002 & n.d.-1.06 & 0.026 \\
\hline PBEB & n.d. -0.001 & n.d. -0.011 & 0.0005 & n.d. -0.062 & 0.003 \\
\hline TBP-DBPE & n.d. -0.002 & n.d. -0.039 & 0.002 & n.d. -0.360 & 0.01 \\
\hline HBB & n.d. -0.015 & n.d. -0.17 & 0.014 & n.d. -0.160 & 0.023 \\
\hline ЕН-ТВВ & n.d. -0.001 & n.d. -0.007 & 0.0004 & n.d.-0.099 & 0.003 \\
\hline TBE & n.d. & n.d. -0.260 & n.d. & n.d. -3.05 & 0.004 \\
\hline ВEH-ТЕВР & n.d. & n.d. -0.004 & 0.0002 & n.d. -0.025 & n.d. \\
\hline DBDPE & n.d.-25.6 & $0.310-81.7$ & 5.92 & $3.52-218$ & 39.5 \\
\hline$\sum$ aBFRs & $0.0006-26.6$ & $0.330-81.8$ & 5.94 & $3.52-219$ & 40.1 \\
\hline syn-DP & n.d. -5.58 & $0.490-189$ & 6.61 & n.d.-1.28 & 0.140 \\
\hline anti-DP & n.d. -4.56 & $0.400-159$ & 5.11 & $0.013-2.80$ & 0.330 \\
\hline DPs & n.d.-10.0 & $0.890-346$ & 11.7 & $0.013-3.94$ & 0.430 \\
\hline
\end{tabular}

$\mathrm{n}$ : number of samples; n.d.: not detected; a: the median of the concentrations of the dissolved and particulate phases summed together.

detection rates of the PBDE congeners (excluding BDE 85) varied from $26 \%$ to $100 \%$ in the water samples (Table S1), which suggested that these compounds were common in the Xiaoqing River basin. BDE 85 was detected only in a few water samples. The concentrations of seven PBDEs (not including BDE 28, 47, and 209) were below the quantifiable limits in at least $70 \%$ of the dissolved samples. However, PBDEs were ubiquitous in the water filters, with all target compounds, except BDE 85 , present in more than $50 \%$ of the samples. The dissolved and particulate concentrations of the 10 PBDEs ( $\sum$ PBDE concentrations) ranged from 0.001 to $0.80 \mathrm{ng} / \mathrm{L}$ (dissolved phase) and from 0.026 to $11.5 \mathrm{ng} / \mathrm{L}$ (particulate phase), with average concentrations of 0.0085 and $1.30 \mathrm{ng} / \mathrm{L}$, respectively (Table 1 ).

The overall $\sum$ PBDE concentrations in the Xiaoqing River Basin, including particulate and dissolved phase samples (1.39-11.5 ng/L), were similar to those in the Three Gorges Dam region of the Yangtze River in China (0.80-17.6 ng/L) (Ge et al., 2014) and Shihwa Lake in Korea (0.16-11.0 ng/L) (Moon et al., 2012). However, they were generally lower than those in the Pearl River Delta of China $(0.340-68.0 \mathrm{ng} / \mathrm{L})$ (Guan et al., 2007), the rivers around Chaohu Lake (China) (0.310$84.0 \mathrm{ng} / \mathrm{L}$ ) (Wang et al., 2013) and a sewage outlet in the Dongjiang River (China) (6.90-470 ng/L) (Zeng et al., 2011) (Table S2). The Pearl River Delta, Chaohu Lake, and the Dongjiang River were impacted by e-waste pollution, industrialization, and industrial wastewater, respectively. However, the $\sum$ PBDE concentrations in the Xiaoqing River Basin were still higher than the levels reported in Jiaozhou Bay (China), Hong Kong (China), and the San Francisco Estuary (USA), all of which have been less impacted by direct emission from HFRs manufacturing (Table S2). In the present study, BDE 209 was the major congener, accounting for $84 \%$ and $93 \%$ in the dissolved and particulate phases, respectively. This finding is consistent with previous studies of air, water, soil, and sediment samples (Liu et al., 2016, Wang et al., 2017, Zhen et al., 2016, Zheng et al., 2015). The highest concentrations of BDE 209 in the water samples in the present were detected at location 3 (11.4 ng/L).

Water samples were analyzed for eight aBFRs. TBE and BEH-TEBP were below their MDLs in the dissolved phase samples (Table 1).
Most of the aBFRs, except for DBDPE, had lower detection rates in the dissolved phase compared with those in the particulate phase. DBDPE was discovered in all samples (both dissolved and particulate phases), with other aBFRs were detected less frequently (PBT: $85 \%$, PBEB: $43 \%$, TBP-DBPE: 58\%, HBB: 68\%, EH-TBB: 55\%, TBE: 15\%, and BEH-TEBP: $33 \%)$. The $\sum$ aBFR concentrations across all samples varied from 0.370 to $107 \mathrm{ng} / \mathrm{L}$ (mean: $14.4 \mathrm{ng} / \mathrm{L}$ ). Of these, DBDPE accounted for $99 \%$ of all $\sum$ aBFR concentrations, with a concentration range of 0.310 $107 \mathrm{ng} / \mathrm{L}$. The DBDPE concentration was much higher than that of BDE 209 in the water samples. The higher concentration of DBDPE in this basin might be consistent with the extensive production and use of DBDPE as a replacement for BDE 209 (Table S5). The concentrations of PBT, TBP-DBPE, HBB, and EH-TBB (in both dissolved and particulate phases) were $0.0002-0.0018 \mathrm{ng} / \mathrm{L}$ (excluding the peak concentration for station 2: $2.04 \mathrm{ng} / \mathrm{L})$, n.d.- $0.039 \mathrm{ng} / \mathrm{L}$, n.d.-0.180 ng/L, and n.d.$0.007 \mathrm{ng} / \mathrm{L}$, respectively, comparable to the congeners of the PBDEs mentioned above. But beyond that, the concentrations of PBEB, TBE and BEH-TEBP were in the ranges of n.d.-0.0110, n.d.-0.260 and n.d.$0.0004 \mathrm{ng} / \mathrm{L}$, respectively.

In this study area, the average concentrations of DBDPE in both particulate and dissolved water samples (0.310-107 ng/L) were lower than those from samples taken from a sewage outlet in the Dongjiang River (9.10-990 ng/L) (Zeng et al., 2011), but two orders of magnitude higher than those from water samples of the Dongjiang River (0.400$1.74 \mathrm{ng} / \mathrm{L}$ ) (He et al., 2016). However, the TBP-DBPE concentrations observed here $(0.005-0.039 \mathrm{ng} / \mathrm{L})$ were a little lower than those of the Elbe River in Central Europe (n.d.-0.07 ng/L) (Moller et al., 2012). Moreover, the total levels of the three aBFRs (HBB, EH-TBB, and TBE) in the present study were lower than those of water samples from the coastal mariculture area in the Bohai Sea, China (HBB, 1.23-9.43 ng/L;EH-TBB, 0.810$6.69 \mathrm{ng} / \mathrm{L}$; TBE, $0.03-0.150 \mathrm{ng} / \mathrm{L}$ ) (Wang et al., 2017). Overall, the range of DBDPE concentrations measured in the present study was higher those in previous studies of aquatic environments around the worldwide. However, concentrations of the remaining seven aBFRs were moderate compared with those in previous studies (Table S2).

Table 1 shows the DPs in all water samples from this study area. DPs are chlorinated flame retardants comprising two isomers, syn-DP and anti-DP. DPs were the dominant HFR components in the water samples, but in sediment DBDPE was the primary compound as mentioned below. The discrepancy between these two compounds in the two phases might be ascribed to the different physicochemical properties or different production and usage. In fact, the annual estimated production of DPs in China is between 2100 and $7000 \mathrm{t}$ (Zhao et al., 2011). The average concentrations of DPs in the water samples exceeded those of the BFRs, thus they deserved more attention. DPs was detected in all water samples, mainly in the particulate phase $(0.890-346 \mathrm{ng} / \mathrm{L})$, and its concentration was one order of magnitude higher than that found in sewage samples from the Dongjiang River (0.170-23.6 ng/L) (Zeng et al., 2011). Mahmood et al., 2015 reported that the range DPs concentrations were from 0.01 to $4.58 \mathrm{ng} / \mathrm{L}$ in water samples in the Chenab River of the Pakistan. He et al., 2016 found that the concentrations of DPs ranged from 0.230 to $0.780 \mathrm{ng} / \mathrm{L}$ in water samples in the Dongjiang River. Qi et al., 2010 found that DPs concentrations in water samples from the Songhua River (China) were n.d.-2.40 ng/L. The relatively high concentrations of DPs in present paper were comparable to those in other studies. The $f_{\text {anti }}$ value is defined as the concentration of antiDP divided by the sum of the concentrations of syn- and anti-DP. The mean $f_{\text {anti }}$ value observed here was $0.43 \pm 0.03$, which was lower than that of commercial DPs products such as OxyChem (0.60) (Liu et al., 2016). This indicated an enrichment of syn-DP in the water samples. This result merited further investigation, as the multiple factors might affect the depletion or enrichment of syn- and anti-DP in water samples. The difference in the DP diastereomer compositions between the water samples and commercial DPs products might be attributed to stereoselective degradation of DPs by microorganisms or to differences in the physicochemical properties of syn- and anti-DP (Hoh et al., 2006). 


\subsection{Concentrations of HFRs in the sediment samples}

Table S1 reports the concentrations of HFR congeners in the sediment samples. Of the 10 PBDE congeners, BDE 209 was detected in all sediment samples, whereas the rest of the PBDE congeners were detected in fewer samples (in order: BDE $28>$ BDE $99=$ BDE $153=$ BDE 183 $>\mathrm{BDE} 47=\mathrm{BDE} 66=\mathrm{BDE} 100>\mathrm{BDE} 154>\mathrm{BDE} 85)$. The mean concentration of $\sum$ PBDE in sediment was $3.66 \mathrm{ng} / \mathrm{g} \mathrm{dw}$ (with a range of $0.130-10.0 \mathrm{ng} / \mathrm{g} \mathrm{dw}$ ). Consistent with previous works (Zhen et al., 2016, Zhu et al., 2013), BDE 209 was the dominant congener in all sediment samples, accounting for $77 \%$ of all $\sum$ PBDE concentrations, followed by BDE 28 (6\%), BDE 47 (5\%), and BDE 99 (4\%). The sum of concentrations of the remaining six PBDE congeners was less than $8 \%$. The concentration of BDE209 ranged from 0.130 to $7.62 \mathrm{ng} / \mathrm{g} \mathrm{dw}$, with a mean concentration of $2.81 \mathrm{ng} / \mathrm{g} \mathrm{dw}$. This mean value was much lower than that detected in sediments from the Dongjiang River (3.83-2517 ng/g dw) (Chen et al., 2013), which passes through a large electronics manufacturing center, as well as commercially-impacted sediments from the Nakdong River, Korea (0.390-190 ng/g dw) (Lee et al., 2015) and in urban sediments from the Ravi River, Pakistan (1.00-2600 ng/g dw) (Syed et al., 2013) (Table S3). The BDE 209 concentrations were comparable with those reported in previous studies (Table S3), but much higher than those in sediments from the Liaohe River Basin, China (0.140-2.70 ng/g dw) (Ma et al., 2016) and the Yellow River estuary (1.16-5.40 ng/g dw) (Yuan et al., 2016). Meanwhile, the sum of the concentrations of the remaining nine PBDE congeners (0.001-5.97 ng/g dw) was much lower than those of sediments from the Ravi River (n.d.-15.0 ng/g dw) (Syed et al., 2013) and the Dongjiang River (0.450-11.8 ng/g dw) (Chen et al., 2013), but somewhat higher than those of sediments in the Yellow River estuary $(0.480-1.07 \mathrm{ng} / \mathrm{g}$ $\mathrm{dw}$ ) (Yuan et al., 2016) and the Bohai Sea (0.100-0.480 ng/g dw) (Barón et al., 2014). Based on these comparisons, it can be concluded that the PBDEs contamination in the Xiaoqing River Basin was moderate.

Eight aBFRs were detected in the surface sediments (in order: DBDPE $>$ TBP-DBPE $>$ PBT $>$ PBEB $=\mathrm{HBB}>\mathrm{EH}-\mathrm{TBB}=\mathrm{TBE}>\mathrm{BEH}-$ TEBP). Unlike the composition characteristics of HFRs in the water samples, DBDPE dominated in the sediment samples, with concentrations that ranged from 46.8 to $218 \mathrm{ng} / \mathrm{g} \mathrm{dw}$, followed by BDE209 (n.d.$7.62 \mathrm{ng} / \mathrm{g} \mathrm{dw})$ and DPs $(0.013-3.94 \mathrm{ng} / \mathrm{g} \mathrm{dw})$. This was similar to the result of a previous study in that DBDPE was the dominant BFR in the sediment of the bays in the Yellow Sea (Zhen et al., 2016b). For PBT, PBEB,
TBP-DBPE and HBB, which had $80 \%$ detection frequencies, their concentrations ranged from n.d.-1.06, n.d.-0.062, n.d.-0.360, and n.d.$0.160 \mathrm{ng} / \mathrm{g} \mathrm{dw}$, respectively. TBB, EH-TBB and BEH-TEBP, were detected in $50 \%, 50 \%$, and $41 \%$ of all samples, respectively, at concentrations of n.d.-0.098 (EH-TBB), n.d.-3.05 (TBE), and n.d.-0.025 ng/g dw (BEHTEBP), respectively. It was noteworthy that, in this area, the sum of the average concentration of the remaining seven aBFRs (except for DBDPE) was similar to that of the less brominated PBDE congeners (except for BDE 209). The surface sediment concentrations of DBDPE measured herein were much higher than those in bay sediments reported previously (Table S3) but they were lower than those measured in the sediments of the Dongjiang River, which have been seriously affected by electronic manufacturing (Chen et al., 2013). Zhu et al., 2013 reported similar individual mean concentration of aBFRs (PBT, HBB, EH-TBB and TBE) in sediments from the Yangzi River estuary. However, the mean concentrations of PBEB and BEH-TEBP measured by Zhu et al., 2013 were somewhat higher than those measured herein. It is obvious that contamination of sediments by DBDPE shown in present study was more serious than that in other areas. As shown in Fig. 2, the highest DBDPE concentration in sediment was observed at site X10. In addition, a high DBDPE concentration in water was also found at site 10 . Hence, we suspect that such high DBDPE concentrations at site 10 might be from a point source of DBDPE nearby. However, the concentrations of the other seven aBFRs were low. This discrepancy might be ascribed to temporal variabilities in aBFR production and use.

In sediments, syn-DP and anti-DP were observed in 95\% and 100\% of samples, respectively, with concentrations that ranged from n.d. to 1.28 (syn-DP) and from 0.013 to $2.80 \mathrm{ng} / \mathrm{g} \mathrm{dw}$ (anti-DP). The summed DP concentrations ranged from 0.013 to $3.94 \mathrm{ng} / \mathrm{g}$ dw with a mean concentration of $0.810 \mathrm{ng} / \mathrm{g} \mathrm{dw}$ in the Xiaoqing River Basin. DPs have been widely detected in sediments worldwide. For instance, Chen et al., 2013 reported DPs concentrations ranging from 0.09 to $28.0 \mathrm{ng} / \mathrm{g} \mathrm{dw}$ in Dongjiang River sediments. Moreover, the levels of DPs measured herein were similar to those in sediments from the Ravi River in Pakistan (Syed et al., 2013). However, the DPs concentrations measured herein were significantly higher than those found in sediments from other areas, including the Qiantang River (nd-1.10 ng/g dw) (Sun et al., 2013), the Songhua River (0.0045-0.16 ng/g dw) (Qi et al., 2010), and Sishili Bay in China (0.0001-0.14 ng/g dw) (Zhao et al., 2011) and San Francisco Bay in the USA (0.100-0.900 ng/g dw) (Klosterhaus et al., 2012). Hence, the DPs contamination in the Xiaoqing River Basin is moderate in comparison with the rest of the world. The

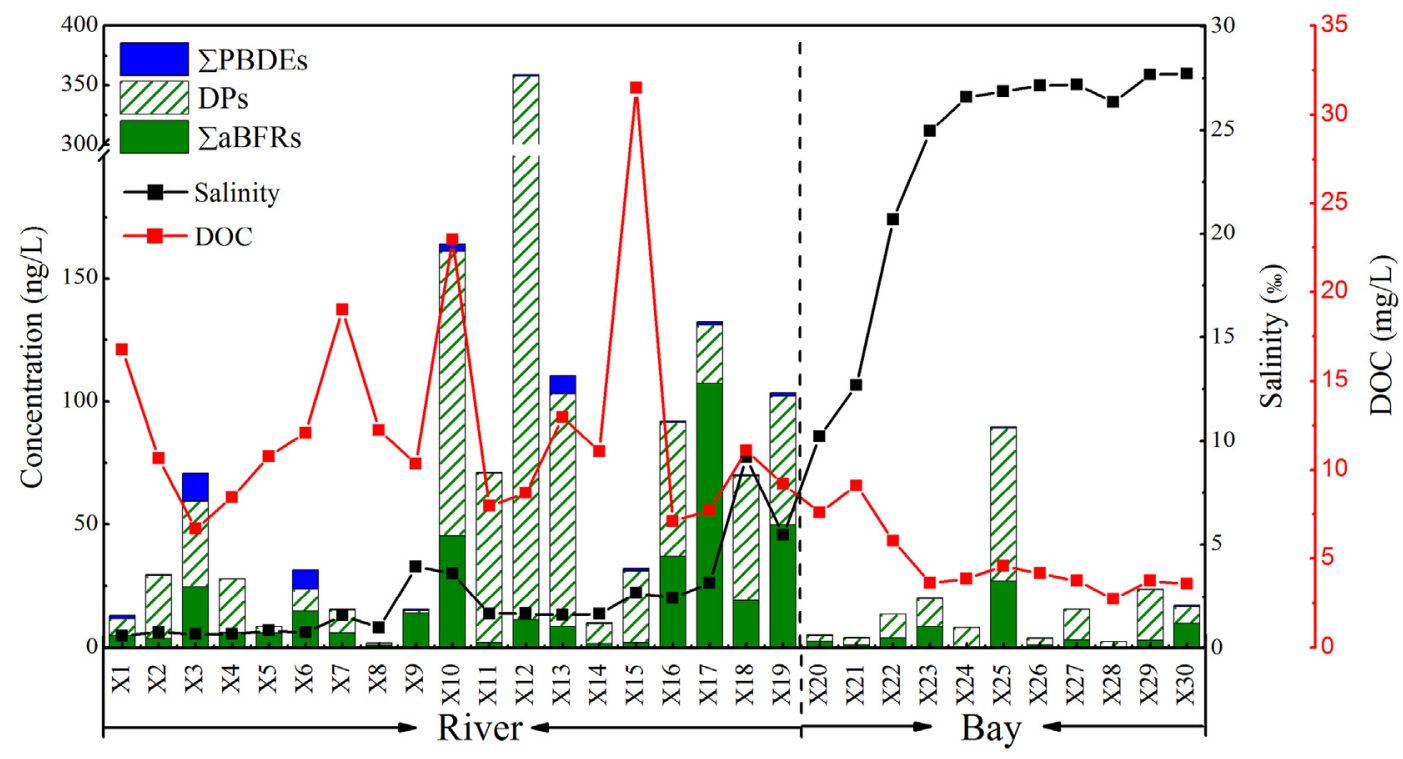

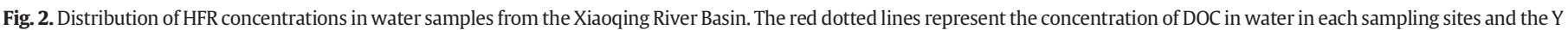
axis (right) in red color is for DOC. The black dotted lines represent the value of salinity in water in each sampling sites and the Y axis (right) in black color is for salinity. 
mean value of $f_{\text {anti }}$ in the Xiaoqing River sediments was $0.67 \pm 0.14$, which was higher than the $f_{a n t i}$ of the water samples $(0.43 \pm 0.03)$ and the commercial DP product OxyChem (0.60), as discussed above. The high $f_{\text {anti }}$ could be explained by the preferential biodegradation of syn-DP in sediments (Zhao et al., 2011) bioaccumulation of syn-DP in benthos (Qi et al., 2010), as well as a stereoselective depletion of synDP in sediments.

\subsection{Spatial distribution and fate of HFRs in the Xiaoqing River Basin}

Based on station locations, the sampling area was divided into two sections: river (X1-X19) and estuary (X20-X30) (Fig. 1).

\subsubsection{Spatial distribution and fate of HFRs in the river samples}

The distributions of HFRs in water and sediment along the sampling transect are shown in Fig. 2 and Fig. 3, respectively. The highest $\sum$ HFR concentration across all river sediment samples was observed at site 10 . Furthermore, a high $\sum$ HFR concentration was also found in the river water sample at site X10 (Fig. 2). Stations X9 and X10 were located near each other in the Zhulong River (a branch of the Xiaoqing River), an area influenced by Huantai County in the northern part of the city of Zibo, China. However, the $\sum$ HFR concentration in the river water samples increased rapidly by a factor of 8 between sites X9 and X10. Heydebreck et al., 2015 also found the highest PFASs concentration of water samples at site X10 in the same sample batch. The industrial area of Huantai County is located in the north of the Zhulong River. We strongly suspected that a substantial industrial point source might be located near site 10 . The highest $\sum$ HFR concentration in the water samples was observed at site X12. Here, a tributary of the Xiaoqing River (Yubei River) lies upstream, and a lower $\sum$ HFR concentration in the water sample was observed at site X11. DPs were the predominant component in water samples. Compared to previous studies (Table S1), there was no report on the comparable DPs in water samples. Such high DPs contamination might be primarily caused by industrial discharge from DP manufacturing sites. Therefore, the high levels of HFRs in the water and sediment at these sites might be largely contributed from industrial activities, specialized for producing or processing HFRs or commercial products containing HFRs.

The largest manufacturing base for BFRs in China - the Binhai Economic Development Zone is located in the city of Weifang, which is an important industrial city located in southeast of the Xiaoqing River.
Previous studies have reported high HFR concentrations in the air, soil, riverine sediments, and human serum from this area (Jin et al., 2011, Pan et al., 2011, Wang et al., 2014). It has also been shown that BFRs in the seawater and the soil around this area can be ascribed to air deposition (Jin et al., 2011, Xie et al., 2011). In this study, high $\sum$ HFR concentrations were also found at sites from X16 to X19, both in water and in sediment samples. Sites X16 and X17 were located at the downstream ends of the Laota River and Xinta River, respectively. Both of these tributaries pass through Weifang and merge into the Xiaoqing River. Lin et al., 2013 and Zhao et al., 2013 also observed that high aBFR concentrations in the atmosphere around Laizhou Bay, and concluded that manufacturing activities were the primary source. Meanwhile, atmospheric deposition, including dry deposition and wet deposition, is a crucial mechanism for removing pollutants from the atmosphere. Thus, our results revealed that HFR contamination from manufacturing might affect the atmosphere, and consequently, the Xiaoqing River and the tributaries of the Laota River and Xinta River.

There is a WWTP upstream of site X3 (Fig. 1), which received municipal waste water from Jinan, China. For the sites X1 to X6, the highest $\sum$ HFR concentrations in both water and sediment samples were both found at site X3. Moreover, the $\sum$ HFRs concentration decreased with distance from the WWTP. Zeng et al., 2014 found high $\sum$ HFR concentrations and high HFR detection in sewage sludge from 62 WWTPs in China. Thus, the WWTP might be another source of HFRs in the Xiaoqing River.

Regarding the distribution of $\sum$ HFR concentrations across water samples and riverine sediments (excluding samples from the bay), the $\sum$ HFR concentration in the sediment of site $\mathrm{X} 7$ was three times higher than that of site X6, but in the water samples, the reverse was ture. It has been shown that total organic carbon (TOC) has a high affinity for BFRs (Zhang et al., 2015). In the present study, DBDPE was the primary component in all sediment samples mentioned above. The TOC at site X7 (3.05\%) was higher than that at site X6 (2.20\%). Hence, TOC might have affected the distribution of HFRs in the Xiaoqing River.

\subsubsection{Spatial distribution and fate of HFRs in the estuarine samples}

Previous studies have also reported that high PBDE concentrations were observed in the rivers (Xiaoqing, Mihe, and Dihe Rivers) around Laizhou Bay, and have suggested that rivers are an important source of PBDEs (Pan et al., 2011). Fig. 3 showed that the $\sum$ HFR concentrations in the estuarine sediment samples in the mouth of the Xiaoqing River

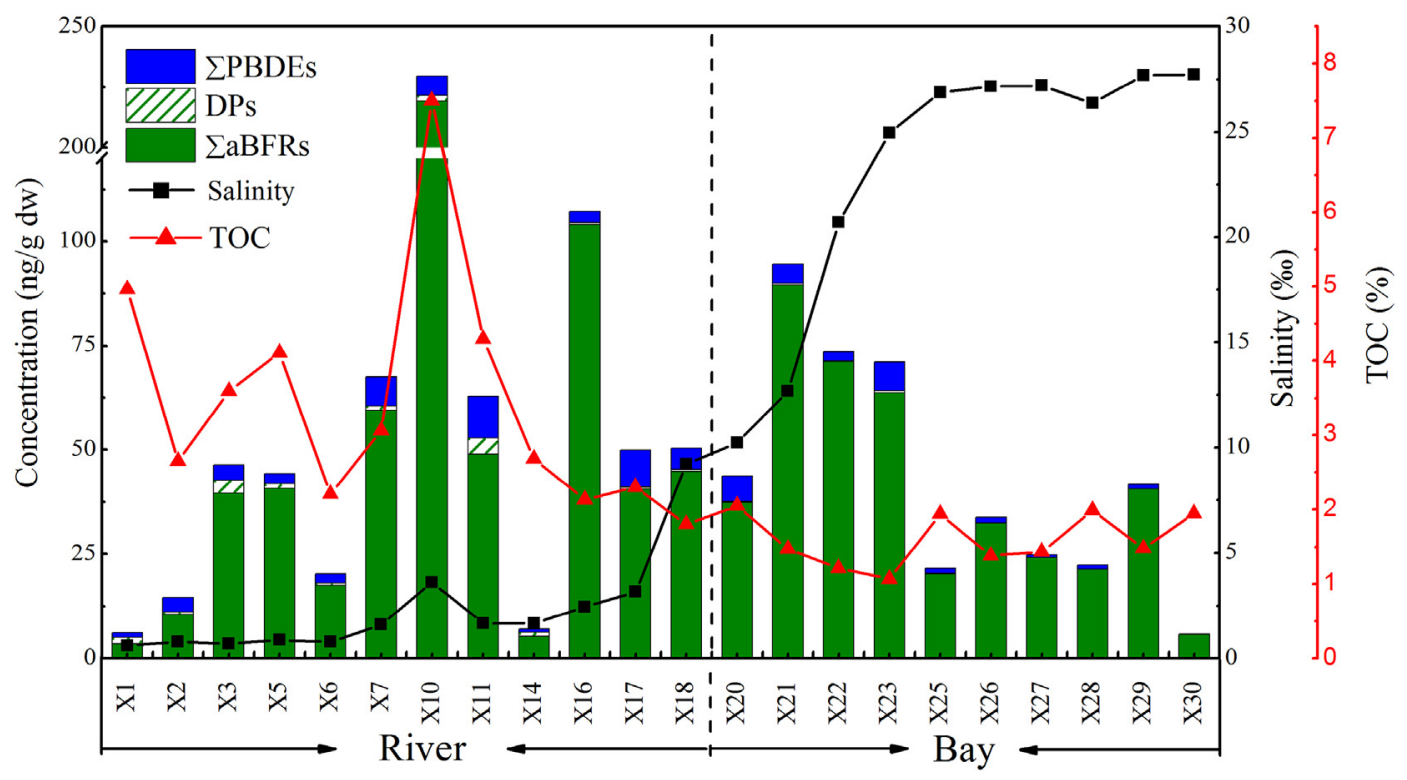

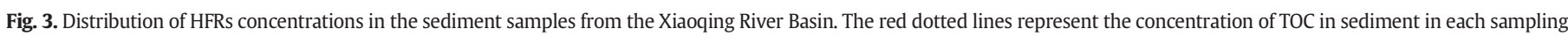

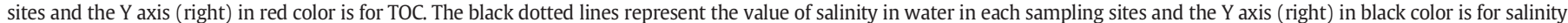


(X20-X23) were higher than those in the estuarine water samples of more distant locations $(\mathrm{X} 25-\mathrm{X} 30)(t$-test, $\mathrm{t}<0, \mathrm{p}<0.05)$ (Table S9). This indicates that the Xiaoqing River might be an important HFR source. At the same longitude, the $\sum$ HFR concentration in the estuarine water samples at sites X23, X25, X27, and X29 were higher than those at sites X24, X26, X28, and X30, respectively. In fact, there are several rivers which are across cities in Laizhou Bay. This phenomenon could be accomplished by riverine input from the four other neighboring rivers (Mi, Jiaolai, Bailang, and Wei Rivers) located in Weifang, southwest of the Laizhou Bay. It is noted that riverine discharge might have played a key role in the distribution of HFRs around Laizhou Bay.

The $\sum$ HFR concentrations in the estuarine water samples declined steadily toward Laizhou Bay owing to dilution with fresh seawater. Interestingly, the levels of $\sum$ HFR of sites X17-X19 were lower than those in Laizhou Bay (sites X20-X23). Fig. 3 showed that the largest variations in salinity was found between sites X20 and X23, demonstrating that this area might be located in the estuarine maximum turbidity zone (MTZ) (Taupp et al., 2016). Previous studies have reported that sediment TOC had stronger sorption of HFRs with high $\mathrm{K}_{\mathrm{ow}}$ (Cai et al., 2012, Wang et al., 2015). In addition, the particulate phase contributed most of the $\sum$ HFR concentrations in the water samples. Hermes and Sikes, 2016 reported that the MTZ had the maximum particulate organic carbon (POC) in the bottom water. The most likely reason is that the high $\sum$ HFR concentrations from sites X20-X23 were caused by the MTZ.

Owing to weak water-solubility and large $\mathrm{K}_{\mathrm{ow}}$ values, HFRs are susceptible to partitioning into sediment, suspended organic matter, and dissolved organic matter (DOC) after being released into water (Wang et al., 2017). Besides, Kuivikko et al., 2010 reported that DOC had a major impact on the partitioning and the fate of hydrophobic contaminants in a coastal environment. In the present study, in the estuarine water samples, weak correlations were found between DOC and less brominated PBDE congeners (BDE 28, BDE 47 and BDE 100). In the estuarine samples (both water and sediment samples), the $\sum$ HFR concentrations varied slightly compared with those in the riverine samples, indicating that the mixing via the current might influence the $\sum$ HFR distribution. Hence, further research is needed to determine the causes and distribution of HFRs contamination in this area.

\subsection{Risk assessment}

Risk assessment of PBDEs was performed (Supporting Information, S1.1, and Figures S1 and S2). The results showed that PBDEs in the water and sediment samples posed a medium ecological risk for benthic animals. Owing to the lack of toxicity data for DPs and DBDPE in water and sediment, this study did not calculated the RQs (risk quotients) for these two components. More attention should be paid to the ecological risk assessment of DPs and DBDPE in the environment because of their high levels in water and sediment samples.

\section{Conclusion}

HFRs were widely detected in the Xiaoqing River Basin. In the water samples, HFRs mainly existed in particulate phase, with DPs and DBDPE the dominant species. However, DBDPE and BDE 209 were the most prevalent compounds in the sediment samples from the Xiaoqing River Basin. The factors that affected the distribution characteristics of $\sum$ HFR concentrations in the Xiaoqing River basin included source, water current, MTZ, DOC, and TOC. Point source, atmospheric deposition, and WWTP discharge were the three main sources of HFR contamination in the Xiaoqing River basin. More research is needed to investigate HFR contamination in rivers around HFR manufacturing bases.

\section{Acknowledgement}

This study was financially supported by the Chinese Academy of Sciences (KZZD-EW-14, XDA11020401, 2013T2Z0032 and 13337KYSB20130013).

\section{Appendix A. Supplementary data}

Supplementary data to this article can be found online at https://doi. org/10.1016/j.scitotenv.2017.10.091.

\section{References}

Barón, E., Santín, G., Eljarrat, E., Barceló, D., 2014. Occurrence of classic and emerging halogenated flame retardants in sediment and sludge from Ebro and Llobregat river basins (Spain). J. Hazard. Mater. 265, 288-295

Cai, M.G., Hong, Q.Q., Wang, Y., Luo, X.J., Chen, S.J., Cai, M.H., Qiu, C.R., Huang, S.Y., Mai, B.X. 2012. Distribution of polybrominated diphenyl ethers and decabromodiphenylethane in surface sediments from the Bering Sea, Chukchi Sea, and Canada Basin. Deep Sea Research Part II: Topical Studies in Oceanography. 81-84, pp. 95-101.

Chen, S., Feng, A., He, M., Chen, M., Luo, X., Mai, B., 2013. Current levels and composition profiles of PBDEs and alternative flame retardants in surface sediments from the Pearl River Delta, southern China: comparison with historical data. Sci. Total Environ. 444, 205-211.

Covaci, A., Harrad, S., Abdallah, M.A., Ali, N., Law, R.J., Herzke, D., de Wit, C.A., 2011. Novel brominated flame retardants: a review of their analysis, environmental fate and behaviour. Environ. Int. 37 (2), 532-556.

Flamretardants-online, 2014. Market study of IHS Consulting, 2014. Accessible at. https:// www.flameretardants-online.com/flame-retardants/market.

Ge, J., Yun, X., Liu, M., Yang, Y., Zhang, M., Wang, J., 2014. Distribution, potential source and ecotoxicological risk of polychlorinated biphenyls and polybrominated diphenyl ethers in the surface water of the Three Gorges Dam region of the Yangtze River, China. Ecotoxicology 23 (6), 978-987.

Guan, Y., Wang, J., Ni, H., Luo, X., Mai, B., Zeng, E., 2007. Riverine inputs of polybrominated diphenyl ethers from the Pearl River Delta (China) to the Coastal Ocean. Environ. Sci. Technol. 41, 6007-6013.

HCEPA, 2016. Wastewater Monitoring Data in 2016. Accessible at. http:// www.hthb.gov.cn/html/list12.html

He, M., Luo, X., Chen, M., Sun, Y., Chen, S., Mai, B., 2012. Bioaccumulation of polybrominated diphenyl ethers and decabromodiphenyl ethane in fish from a river system in a highly industrialized area, South China. Sci. Total Environ. 419, 109-115.

He, M., Li, Q., Zhao, J., Wang, D., 2016. Concentrations and partitioning of halogenated flame retardants in industrial water of Dongjiang River. Environ. Sci. 37 (7), 2539-2546.

Hermes, A.L., Sikes, E.L., 2016. Particulate organic matter higher concentrations, terrestrial sources and losses in bottom waters of the turbidity maximum, Delaware Estuary, USA. Estuar. Coast. Shelf Sci. 180, 179-189.

Heydebreck, F., Tang, J., Xie, Z., Ebinghaus, R., 2015. Alternative and legacy perfluoroalkyl substances: differences between European and Chinese river/estuary systems. Environ. Sci. Technol. 49 (14), 8386-8395.

Hoh, E., Zhu, L., Hites, R.A., 2006. Dechlorane Plus, a Chlorinated Flame Retardant, in the Great Lakes.

Jia, H., Sun, Y., Liu, X., Yang, M., Wang, D., Qi, H., Shen, L., Sverko, E., Reiner, E.J., Li, Y.F., 2011. Concentration and bioaccumulation of dechlorane compounds in coastal environment of northern China. Environ. Sci. Technol. 45 (7), 2613-2618.

Jiang, T., Skyllberg, U., Bjorn, E., Green, N.W., Tang, J., Wang, D., Gao, J., Li, C., 2017. Characteristics of dissolved organic matter (DOM) and relationship with dissolved mercury in Xiaoqing River-Laizhou Bay estuary, Bohai Sea, China. Environ. Pollut. 223, 19-30.

Jin, J., Wang, Y., Liu, W., Yang, C., Hu, J., Cui, J., 2011. Polybrominated diphenyl ethers in atmosphere and soil of a production area in China: levels and partitioning. J. Environ. Sci. 23 (3), 427-433.

Ju, T., Ge, W., Jiang, T., Chai, C., 2016. Polybrominated diphenyl ethers in dissolved and suspended phases of seawater and in surface sediment from Jiaozhou Bay. North China. Sci Total Environ 557-558, 571-578.

Kim, U.J., Lee, I.S., Oh, J.E., 2016. Occurrence, removal and release characteristics of dissolved brominated flame retardants and their potential metabolites in various kinds of wastewater. Environ. Pollut. 218, 551-557.

Klosterhaus, S.L., Stapleton, H.M., La Guardia, M.J., Greig, D.J., 2012. Brominated and chlorinated flame retardants in San Francisco Bay sediments and wildlife. Environ. Int. 47, 56-65.

Kuivikko, M., Sorsa, K., Kukkonen, J.V., Akkanen, J., Kotiaho, T., Vahatalo, A.V., 2010. Partitioning of tetra- and pentabromo diphenyl ether and benzo[a]pyrene among water and dissolved and particulate organic carbon along a salinity gradient in coastal waters. Environ. Toxicol. Chem. 29 (11), 2443-2449.

Lee, I., Kang, H., Kim, U., Oh, J., 2015. Brominated flame retardants in Korean river sediments, including changes in polybrominated diphenyl ether concentrations between 2006 and 2009. Chemosphere 126, 18-24.

Lin, Y., Qiu, X., Zhao, Y., Ma, J., Yang, Q., Zhu, T., 2013. Polybromobenzene pollutants in the atmosphere of North China: levels, distribution, and sources. Environ. Sci. Technol. 47 (22), 12761-12767.

Liu, L.Y., Salamova, A., He, K., Hites, R.A., 2015. Analysis of polybrominated diphenyl ethers and emerging halogenated and organophosphate flame retardants in human hair and nails. J. Chromatogr. A 1406, 251-257. 
ARTICLE IN PRESS

8

X. Zhen et al. / Science of the Total Environment $x x x$ (2017) $x x x-x x x$

Liu, D., Lin, T., Shen, K., Li, J., Yu, Z., Zhang, G., 2016. Occurrence and concentrations of halogenated flame retardants in the atmospheric fine particles in Chinese cities. Environ. Sci. Technol. 50 (18), 9846-9854.

Ma, X., Zhang, H., Yao, W., Guo, W., Li, D., Yao, Z., Chen, J., 2016. Occurrence and bioaccumulation of polybrominated diphenyl ethers in sediments and paddy ecosystems of Liaohe River Basin, northeast China. J. Environ. Sci. 43, 250-256.

Mahmood, A., Malik, R.N., Li, J., Zhang, G., 2015. Distribution, congener profile, and risk of polybrominated diphenyl ethers and dechlorane plus in water and sediment from two tributaries of the Chenab River, Pakistan. Arch. Environ. Contam. Toxicol. 68 (1), 83-91.

Moller, A., Xie, Z., Sturm, R., Ebinghaus, R., 2010. Large-scale distribution of dechlorane plus in air and seawater from the Arctic to Antarctica. Environ. Sci. Technol. 44, 8977-8982.

Moller, A., Xie, Z., Caba, A., Sturm, R., Ebinghaus, R., 2012. Occurrence and air-seawater exchange of brominated flame retardants and dechlorane plus in the North Sea. Atmos. Environ. 46, 346-353.

Moon, H.B., Choi, M., Yu, J., Jung, R.H., Choi, H.G., 2012. Contamination and potential sources of polybrominated diphenyl ethers (PBDEs) in water and sediment from the artificial Lake Shihwa, Korea. Chemosphere 88 (7), 837-843.

Pan, X., Tang, J., Li, J., Zhong, G., Chen, Y., Zhang, G., 2011. Polybrominated diphenyl ethers (PBDEs) in the riverine and marine sediments of the Laizhou Bay area, North China. J. Environ. Monit. 13 (4), 886-893.

Qi, H., Liu, L.Y., Jia, H.L., Li, Y.F., Ren, N.I., You, H., Shi, X.Y., Fan, L.L., Ding, Y.S., 2010. Dechlorane plus in surficial water and sediment in a Northeastern Chinese River. Environ. Sci. Technol. 44, 2305-2308.

Sun, J., Zhang, A., Fang, L., Wang, J., Liu, W., 2013. Levels and distribution of dechlorane plus and related compounds in surficial sediments of the Qiantang River in eastern China: the results of urbanization and tide. Sci. Total Environ. 443, 194-199.

Syed, J.H., Malik, R.N., Li, J., Wang, Y., Xu, Y., Zhang, G., Jones, K.C., 2013. Levels, profile and distribution of dechloran plus (DP) and polybrominated diphenyl ethers (PBDEs) in the environment of Pakistan. Chemosphere 93 (8), 1646-1653.

Taupp, T., Hellmann, C., Gergs, R., Winkelmann, C., Wetzel, M.A., 2016. Life under exceptional conditions-isotopic niches of benthic invertebrates in the estuarine maximum turbidity zone. Estuar. Coasts 40 (2), 502-512.

Wang, X., Xi, B., Huo, S., Deng, L., Pan, H., Xia, X., Zhang, J., Ren, Y., Liu, H., 2013. Polybrominated diphenyl ethers occurrence in major inflowing rivers of Lake Chaohu (China): characteristics, potential sources and inputs to lake. Chemosphere 93 (8), 1624-1631.

Wang, Y., Xu, M., Jin, J., He, S., Li, M., Sun, Y., 2014. Concentrations and relationships between classes of persistent halogenated organic compounds in pooled human serum samples and air from Laizhou Bay. China. Science of The Total Environment 482-483, 276-282.

Wang, X., Chen, L., Wang, X., Zhang, Y., Zhou, J., Xu, S., Sun, Y., Wu, M., 2015. Occurrence, profiles, and ecological risks of polybrominated diphenyl ethers (PBDEs) in river sediments of Shanghai, China. Chemosphere 133, 22-30.

Wang, Y., Wu, X., Zhao, H., Xie, Q., Hou, M., Zhang, Q., Du, J., Chen, J., 2017. Characterization of PBDEs and novel brominated flame retardants in seawater near a coastal mariculture area of the Bohai Sea, China. Sci. Total Environ. 580, 1446-1452.
Wu, B., Liu, S., Guo, X., Zhang, Y., Zhang, X., Li, M., Cheng, S., 2012. Responses of mouse liver to dechlorane plus exposure by integrative transcriptomic and metabonomic studies. Environ. Sci. Technol. 46 (19), 10758-10764.

Xie, Z., Moller, A., Ahrens, L., Sturm, R., Ebinghaus, R., 2011. Brominated flame retardants in seawater and atmosphere of the Atlantic and the Southern Ocean. Environ. Sci. Technol. 45 (5), 1820-1826.

Xiong, J., Li, G., An, T., Zhang, C., Wei, C., 2016. Emission patterns and risk assessment of polybrominated diphenyl ethers and bromophenols in water and sediments from the Beijiang River, South China. Environ. Pollut. 219, 596-603.

Yuan, Z., Liu, G., Lam, M.H., Liu, H., Da, C., 2016. Occurrence and levels of polybrominated diphenyl ethers in surface sediments from the Yellow River Estuary, China. Environ. Pollut. 212, 147-154.

Zeng, Y., Luo, X., Sun, Y., Yu, L., Chen, S., Mai, B., 2011. Concentration and emission fluxes of halogenated flame retardants in sewage from sewage outlet in Dongjiang River. Chinese. J. Environ. Sci. 32 (10), 2891-2895.

Zeng, L., Yang, R., Zhang, Q., Zhang, H., Xiao, K., Zhang, H., Wang, Y., Lam, P.K., Jiang, G., 2014. Current levels and composition profiles of emerging halogenated flame retardants and dehalogenated products in sewage sludge from municipal wastewater treatment plants in China. Environ. Sci. Technol. 48 (21), 12586-12594.

Zhang, X., Luo, X., Chen, S., Wu, J., Mai, B., 2009. Spatial distribution and vertical profile of polybrominated diphenyl ethers, tetrabromobisphenol A, and decabromodiphenylethane in river sediment from an industrialized region of South China. Environ. Pollut. 157 (6), 1917-1923.

Zhang, Z.-W., Sun, Y.-X., Sun, K.-F., X-R, Xu, Yu, S., Zheng, T.-L., et al., 2015. Brominated flame retardants in mangrove sediments of the Pearl River Estuary, South China: spatial distribution, temporal trend and mass inventory. Chemosphere 123, 26-32.

Zhao, Z., Zhong, G., Möller, A., Xie, Z., Sturm, R., Ebinghaus, R., Tang, J., Zhang, G., 2011. Levels and distribution of dechlorane plus in coastal sediments of the Yellow Sea, North China. Chemosphere 83 (7), 984-990.

Zhao, Y., Ma, J., Qiu, X., Lin, Y., Yang, Q., Zhu, T., 2013. Gridded field observations of polybrominated diphenyl ethers and decabromodiphenyl ethane in the atmosphere of north China. Environ. Sci. Technol. 47 (15), 8123-8129.

Zhen, X., Tang, J., Xie, Z., Wang, R., Huang, G., Zheng, Q., Zhang, K., Sun, Y., Tian, C., Pan, X., Li, J., Zhang, G., 2016. Polybrominated diphenyl ethers (PBDEs) and alternative brominated flame retardants (aBFRs) in sediments from four bays of the Yellow Sea, North China. Environ. Pollut. 213, 386-394.

Zheng, Q., Nizzetto, L., Li, J., Mulder, M.D., Sanka, O., Lammel, G., Bing, H., Liu, X., Jiang, Y., Luo, C., Zhang, G., 2015. Spatial distribution of old and emerging flame retardants in Chinese forest soils: sources, trends and processes. Environ. Sci. Technol. 49 (5), 2904-2911.

Zhu, B., Lam, J.C.W., Yang, S., Lam, P.K.S., 2013. Conventional and emerging halogenated flame retardants (HFRs) in sediment of Yangtze River Delta (YRD) region, East China. Chemosphere 93 (3), 555-560.

Please cite this article as: Zhen, X., et al., From headwaters to estuary: Distribution and fate of halogenated flame retardants (HFRs) in a river basin

near the largest HFR man..., Sci Total Environ (2017), https://doi.org/10.1016/j.scitotenv.2017.10.091 